\title{
Article \\ Clinical Evaluation of Resin Composite CAD/CAM Restorations Placed by Undergraduate Students
}

\author{
Valentin Vervack*, Peter De Coster and Stefan Vandeweghe
}

Reconstructive Dentistry, Dental School, Ghent University Hospital, Entrance 25, 9000 Ghent, Belgium; Peter.DeCoster@ugent.be (P.D.C.); stefan.vandeweghe@ugent.be (S.V.)

* Correspondence: valentin.vervack@ugent.be; Tel.: +32-494-35-64-67

check for updates

Citation: Vervack, V.; De Coster, P.; Vandeweghe, S. Clinical Evaluation of Resin Composite CAD/CAM

Restorations Placed by

Undergraduate Students. J. Clin. Med. 2021, 10, 3269. https://doi.org/ $10.3390 /$ jcm 10153269

Academic Editors:

Gianrico Spagnuolo and

Emmanuel Andrès

Received: 9 June 2021

Accepted: 22 July 2021

Published: 24 July 2021

Publisher's Note: MDPI stays neutral with regard to jurisdictional claims in published maps and institutional affiliations.

Copyright: (C) 2021 by the authors. Licensee MDPI, Basel, Switzerland. This article is an open access article distributed under the terms and conditions of the Creative Commons Attribution (CC BY) license (https:// creativecommons.org/licenses/by/ $4.0 /)$.

\begin{abstract}
To evaluate the clinical outcomes of resin composite CAD/CAM restorations in a prospective cohort study, and to assess patient and operator satisfaction after restoration placement, 59 indirect resin composite were placed by supervised undergraduate students, of which 43 restorations were followed over a mean period of 28 months (14-44 months) and evaluated using USPHS criteria. Patient and operator satisfaction levels were assessed using a visual analogue scale (VAS) after restoration placement. A total of 37 patients and 47 restorations were included for further study. Four teeth were extracted-three due to extensive drug-induced secondary caries in the same patient, and one tooth due to large periapical periodontitis after 44 months of service. The overall survival rate was $91.4 \%$, and success rate was $87.2 \%$. Differences between baseline and endpoint scores were significant for marginal discoloration $(p<0.05)$ and adaptation $(p<0.001)$. Color match $(p<0.05)$ and surface texture $(p<0.001)$ differed significantly, affecting all restoration types. VAS scores for patient and operator satisfaction showed a significant rank correlation $(p<0.01)$, and pairwise comparison showed significant differences for mean overall patient and operator VAS scores $(p<0.001)$. Lava Ultimate CAD/CAM may be considered a suitable material for overlays and endocrown restorations when combined with IDS, air abrasion, and MDP-containing adhesive systems. Marginal disintegration may present in inlays and onlays over time.
\end{abstract}

Keywords: computer-aided design; dental restorations; permanent; undergraduate; students

\section{Introduction}

For many clinicians, direct composite resin restorations are the first choice when treating decayed teeth. A number of technical limitations, such as anatomical challenges in teeth with major substrate loss and marginal leakage associated with deep proximal boxes, as well as the often disappointing lifespan of composites, have legitimized the indirect restorative approach combining extra-oral fabrication and the use of materials with superior mechanical properties. Over the past decades, monolithic computer assisted design-computer assisted machining (CAD/CAM) restorations have gained popularity and have started to replace large direct composite buildups. The digitalization, and more specifically the introduction of chairside CAD/CAM fabrication units, has made the workflow for the manufacturing of indirect restorations easier, faster, and more accurate compared to the conventional workflow using impressions and cast models [1]. Evidence has been produced that a full-digital workflow offers more accurately fitting intracoronal restorations and complete crowns as well as fixed partial dentures [2-4]. According to Nedelcu et al. [5], digital data capturing can reliably replace conventional impression-taking when restoring up to ten units.

In terms of efficiency, the digital workflow offers some distinct advantages over the conventional workflow. Intra-oral scanning (IOS) and digitization of the dentition and the subsequent creation of a virtual cast eliminates two steps of the conventional workflow: the conventional impression and the fabrication of the gypsum cast. This simplification adds to the accuracy of the (virtual) master model but also reduces the working time. Overall, 
a digital workflow requires less chairside time for the dentist and less working time for the dental technician as compared to the conventional workflow [6-8]. Nevertheless, the learning curve of the IOS procedure represents a possible limitation for competent use. Recent studies verified that learning curves are influenced not only by individual factors such as previous experience and motivation, but also by the IOS system itself and repetition of practice $[9,10]$. Marti et al. [11] reported that the learning rate with older IOS devices was longer and led to a less positive student attitude towards digital scanning than with recent devices. According to $\mathrm{Al} \mathrm{Hamad}$ et al. [9], a learning phase of five trials was needed to achieve a competence of $80 \%$ of the practitioner's best performance. The scanning time and difficulty level decreased with the repetitive use of IOS. Other authors found that students roughly take the same amount of time for digital impressions but take significantly more time for a conventional impression in comparison with graduated dentists [12-15]. Furthermore, the learning curve for dental students can be different depending on the used IOS system [16,17].

Routinely used chairside CAD/CAM materials for monolithic restorations include glass ceramics and metal-oxide ceramics. Lithium disilicate reinforced glass ceramics present a three-point flexural strength around $350 \mathrm{MPa}$ and offer natural esthetics due to favorable translucency values [18]. These materials have demonstrated excellent clinical survival rates between $83.5 \%$ and $99 \%$ after 10 years, depending on the type of restoration and the location in the dental arch [19-21]. Metal-oxide ceramics, more specifically yttriastabilized tetragonal zirconia, offer an even higher flexural strength depending on their composition, ranging up to $1450 \mathrm{MPa}$, and can therefore be reliably used for posterior complete crowns as well as for long-span fixed partial dentures [22,23]. More recently, most manufacturers have expanded their range of zirconia materials by increasing the yttria content up to $5 \mathrm{wt} \%$, thereby increasing the cubic crystal phase to $50 \%$ and higher [24]. Although this microstructural modification has reduced the material's fracture toughness, it has improved the optical properties, namely in obtaining a degree of translucency close to glass ceramics $[25,26]$.

In recent years, new resin-based CAD/CAM materials have been introduced, which combine the flexibility and ease of use of resin with the durability and surface stability of ceramic materials [27]. It was reported that these resin-containing CAD/CAM materials, referred to as hybrid ceramics (e.g., Enamic) or resin composite (e.g., LAVA Ultimate and Cerasmart), cause less wear on the opposing dentition compared to glass-ceramics and are easier to mill, polish, and adjust [28,29]. In addition, the marginal integrity is superior to that of glass ceramics due to a lower brittleness [30]. Resin composite CAD/CAM restorations present a better overall mechanical performance than conventional resin composite due to their higher degree of polymerization [31,32]. Unlike indirect resin composites, direct resin composites often suffer from marked polymerization shrinkage and stress, which may cause enamel cracks, debonding of the hybrid layer and thus post-op hypersensitivity and a higher risk for secondary caries [33,34]. These new materials also offer a more efficient fabrication than their ceramic homologues since less milling time, fewer milling tools, and no post milling furnace firing are needed.

Lava Ultimate (3M Espe, Seefeld, Germany) was one of the earliest introduced monolithic resin composite CAD/CAM materials with a total nanoceramic material content by weight of approximately $80 \%$ and a flexural strength of $200 \mathrm{MPa}$. Its zirconia-silica nanocluster particles are synthesized via a proprietary process from $20 \mathrm{~nm}$ silica particles and $4-11 \mathrm{~nm}$ zirconia particles, producing an average nanocluster particle size of $0.6-10$ micrometers. The indications include veneers and intra-coronal restorations, such as inlays, onlays, and overlays. The number of clinical studies involving Lava Ultimate restorations, however, is presently limited. In a recent split-mouth study, Souza et al. [35] reported a 100\% clinical success rate of both lithium disilicate and Lava Ultimate onlays over a 1-year period. When comparing Lava Ultimate and direct composite resin restorations outcomes after 2 years of service, Tunac et al. [36] confirmed a 100\% retention rate and no significant differences between the materials in any of the clinical criteria. Fasbinder et al. [37] re- 
ported a Kaplan-Meier probability for onlay fracture of 0.083 (CI 0.036; 0.189) after 5 years, which was not significantly different from leucite-reinforced ceramic.

Although CAD/CAM resin composites have been recommended for indirect restorative treatment without entailing failures intrinsic to all-ceramic materials, such as chipping, concerns have been raised about their clinical performance. Debonding and cohesive fractures have been reported by previous authors and have been linked to the material's resilience, leading to a revision of the clinical indications in 2015. Although Lava Ultimate has been used for over 7 years, independent studies evaluating the clinical performance are scarce [35-39]. Therefore, the purpose of this clinical trial is to evaluate the mid-term outcomes of resin composite intracoronal chairside CAD-CAM restorations up to 44 months using internationally accepted USPHS standards. The study also aims at evaluating the patient and operator satisfaction immediately after placement of the restoration.

\section{Materials and Methods}

A prospective clinical study was designed in compliance with the Declaration of Helsinki, and the study protocol was approved by the Ethical Committee of the Ghent University Hospital (2015/0144). Patients aged 18 years and older requiring restoration of a decayed molar or premolar involving 3 surfaces or more were recruited in the dental clinic of the Ghent University Hospital. Patients with parafunctions and high caries risk and teeth that are in need of full crown preparations were excluded from the study. All patients were treated by undergraduate dental students (4th and 5th year of dental school) under supervision of an experienced dentist. All students already received preclinical training in indirect restorative dentistry as part of their dental education and an additional practical training in digital impression taking. Patients were informed about the study protocol and had to provide written informed consent prior to enrollment in the study.

After caries removal or elimination of defective restorative material, minimal tooth preparation was performed to maintain as much sound tooth structure as possible. Involved weakened cusps (less than $1.5-2 \mathrm{~mm}$ thickness) were reduced by $1.5 \mathrm{~mm}$; the butt joint margins were designed to be sharp, and the internal line angles were rounded. Immediate dentin sealing (IDS) was applied under a rubber dam using a 2 step self-etch adhesive system (Clearfill SE bond, Kuraray, Tokyo, Japan) and a flowable composite liner (SDR, Dentsply-Sirona, St. York, PA, USA). Deep subgingival margins were elevated, and undercuts were filled using a micro-hybrid direct composite (Clearfill AP-X, Kuraray, Tokyo, Japan). The remaining oxygen inhibited layer was covered with glycerin gel and light cured. The enamel was cleared of any adhesive using a fine diamond bur. Contrast powder was applied, and a digital impression was made using an intra-oral scanner, based on the principle of active wavefront sampling (True Definition, 3M Espe, Seefeld, Germany). A provisional restoration was made chairside from a bis-acrylic composite (Protemp 4, 3M Espe, Seefeld, Germany), based on a putty taken before start of the treatment (Exaflex ${ }^{\circledR}$ Putty, GC, Tokyo, Japan) and fixated using a temporary cement (Rely X Temp, 3M Espe, Seefeld, Germany). The digital impression was sent to a milling center (DPI Lava Milling Center, Anderlecht, Belgium), where the restoration was designed and milled from a nanoceramic particle reinforced resin composite block (Lava Ultimate, 3M Espe, Seefeld, Germany). The unfinished restoration was sent back to the dental school, where it was polished and stained (Sinfony, 3M Espe, Seefeld, Germany) by the undergraduate students.

Prior to the final cementation, the temporary restoration was removed, and the preparation was sandblasted using $27 \mu \mathrm{m} \mathrm{Al}_{2} \mathrm{O}_{3}$ particles (Rondoflex, Kavo, Biberach an der Riss, Germany) to remove cement remnants and to reactivate the IDS layer. The enamel was etched using phosphoric acid 37\% for $20 \mathrm{~s}$, and a universal adhesive (Scotchbond Universal, 3M Espe, Seefeld, Germany) was applied and left uncured. The intaglio of the restoration was sandblasted using $27 \mu \mathrm{m} \mathrm{Al}_{2} \mathrm{O}_{3}$ particles and a universal adhesive (Scotchbond Universal) was applied without light-curing. The restorations were then luted using a dual-cure adhesive resin cement (Rely X Ultimate, 3M Espe, Seefeld, Germany). After seating, tack-curing was performed for $2 \mathrm{~s}$, whereafter the cement overflow was 
removed using a sharp scaler. After removal of the cement remnants, the margins were polished using a fine diamond bur and polishing rubbers. All clinical steps were performed using rubber-dam isolation.

One independent evaluator was calibrated and tasked to examine all restorations in the study. Clinical assessments were made at baseline (one week after placement) and at follow-up examination sessions using modified USPHS criteria (Table 1) for retention, color match, marginal discoloration, marginal adaptation, secondary caries, anatomical form, and surface texture. Periapical radiographs were taken to verify the correct seating of the restoration and to detect secondary caries at follow-up examinations. Vestibular, lingual, and occlusal views were documented using clinical pictures.

Table 1. Modified USPHS criteria.

\begin{tabular}{ccc}
\hline & Score & Criteria \\
\hline Retention & Alpha & No loss of restorative material \\
& Charlie & Any loss of restorative material \\
\hline Color Match & Alpha & Mimics tooth \\
& Bravo & Acceptable mismatch \\
& Charlie & Unacceptable mismatch \\
\hline Marginal Discoloration & Alpha & No discoloration \\
& Bravo & Discoloration without axial penetration \\
& Charlie & Discoloration with axial penetration \\
\hline Secondary Caries & Alpha & No caries present \\
& Charlie & Caries present \\
\hline Anatomic Form & Alpha & Continuous \\
& Bravo & Slight discontinuity \\
& Charlie & Discontinous, failure \\
\hline Marginal Adaptation & Alpha & Closely adapted, no detectable margin \\
& Bravo & Detectable margin clinically acceptable \\
& Charlie & Marginal crevice, clinical failure \\
\hline Surface Texture & Alpha & Enamel like Surface \\
& Bravo & Surface rougher than enamel, clinically acceptable \\
& Charlie & Surface unacceptably rough \\
\hline
\end{tabular}

The restorative outcome was defined in terms of restoration success, restoration survival, and tooth survival. Restoration success means that no reversible or irreversible complications occurred to the restoration or the tooth. Restoration survival means that reversible complications occurred over time, but it also means that these could be repaired. Complications included chipping, minor fractures, and debonding. Tooth survival means that the tooth was still present at the time of evaluation. In the case of loss of the restoration, the tooth could be restored with a new direct or indirect restoration.

Patient and operator satisfaction were assessed using a visual analogue scale (VAS) questionnaire (see Table 2, recorded as a VAS score on a line from 0 to $100 \mathrm{~mm}$, with $0 \mathrm{~mm}$ being very bad, $100 \mathrm{~mm}$ being excellent). Patients were asked to mark for each question the respective VAS, which was a $100 \mathrm{~mm}$ straight horizontal line with the left end indicating "not at all satisfied" and the right end "very satisfied". The satisfaction value was determined by the distance from the left end of the scale to the mark in millimeters and expressed as percentage ( $10 \mathrm{~mm}$ corresponds to $10 \%, 20 \mathrm{~mm} 20 \%$, etc.). The aspects addressed in the patient satisfaction questionnaire were the IOS procedure, the esthetic outcome, and the functional comfort provided by the restoration. Operator satisfaction was rated with respect to the overall restorative procedure, the IOS procedure, the final design of the restoration, the ease of placement of the restoration, and the result in terms of esthetics, color, and shape of the restoration. In addition, the students were asked to rate their satisfaction with the digital workflow as compared to the conventional workflow. 
Table 2. Patient and practitioner questionnaire.

\begin{tabular}{|c|c|c|c|}
\hline \multirow{2}{*}{$\begin{array}{c}\text { Patient } \\
\text { satisfaction }\end{array}$} & 1 & How did you experience the intra-oral scanning procedure & \\
\hline & $\begin{array}{l}2 \\
3\end{array}$ & How would you rate your final restoration in terms of & $\begin{array}{c}\text { esthetics } \\
\text { functionality }\end{array}$ \\
\hline \multirow[t]{6}{*}{$\begin{array}{l}\text { Practitioner } \\
\text { satisfaction }\end{array}$} & 1 & How did you experience & the overall procedure \\
\hline & $\begin{array}{l}2 \\
3 \\
4\end{array}$ & & $\begin{array}{l}\text { the intra oral scanning } \\
\text { the designing of the restoration } \\
\text { the placement of the restoration }\end{array}$ \\
\hline & 5 & How would you rate the overall esthetic appearance of the restoration & \\
\hline & 6 & How would you rate the color of the restoration & \\
\hline & 7 & How would you rate the shape of the restoration & \\
\hline & 8 & Would you prefer digital or conventional impression taking? & \\
\hline
\end{tabular}

A Wilcoxon signed-rank test for dependent samples was used to compare the baseline and follow-up USPHS criteria and also to compare the mean VAS scores between patients and operators. A Kruskal-Wallis test with post-hoc pairwise comparison and Bonferroni correction as well as Pearson's Chi-squared test were used to analyze the statistical differences between the USPHS criteria of the restorations, grouped as onlays (incl. inlays), overlays, and endocrowns. Spearman's coefficient indicated the rank correlation between patient and operator satisfaction. All statistics were performed using IBM SPSS Statistics 27 (IBM Corporation, Armonk, NY, USA)

\section{Results}

A total of 45 patients were enrolled in the study: 17 males and 28 females with a mean age of $48 \pm 13$ years (range 21-83 years); 59 restorations were initially placed in 43 molars and 16 premolars, including 27 overlays, 16 endocrowns, 12 onlays, and 4 inlays. Out of all patients, 11 of them with 12 restorations did not return for their follow-up examinations and were considered as drop-outs. Four teeth were extracted-three due to extensive drug-induced secondary caries in the same patient, and one due to large periapical periodontitis. In total, 34 patients and 43 restorations were included in the study for qualitative assessment. Figure 1 illustrates the flow of patients and restorations enrollment for both the evaluation of restoration survival and the qualitative assessment by using USPHS criteria. Tables 3 and 4 display the distribution of the location of the included restorations and the restoration types.

Table 3. Distribution of involved teeth $(N=43)$ in the study population.

\begin{tabular}{ccccccc}
\hline Teeth & 1st PM & 2nd PM & 1st $\mathbf{M}$ & 2nd $\mathbf{M}$ & 3rd $\mathbf{M}$ & Total \\
\hline Maxillary & 1 & 1 & 6 & 2 & 1 & 11 \\
Mandibular & 2 & 6 & 15 & 9 & 0 & 32 \\
\hline Totals & 3 & 7 & 21 & 11 & 1 & 43 \\
\hline
\end{tabular}

Table 4. Distribution of the involved restoration types.

\begin{tabular}{cccc}
\hline & Premolars & Molars & Total \\
\hline In-/onlay & 4 & 8 & 12 \\
Overlay & 3 & 18 & 21 \\
Endocrown & 3 & 7 & 10 \\
\hline Total & 10 & 33 & 43 \\
\hline
\end{tabular}




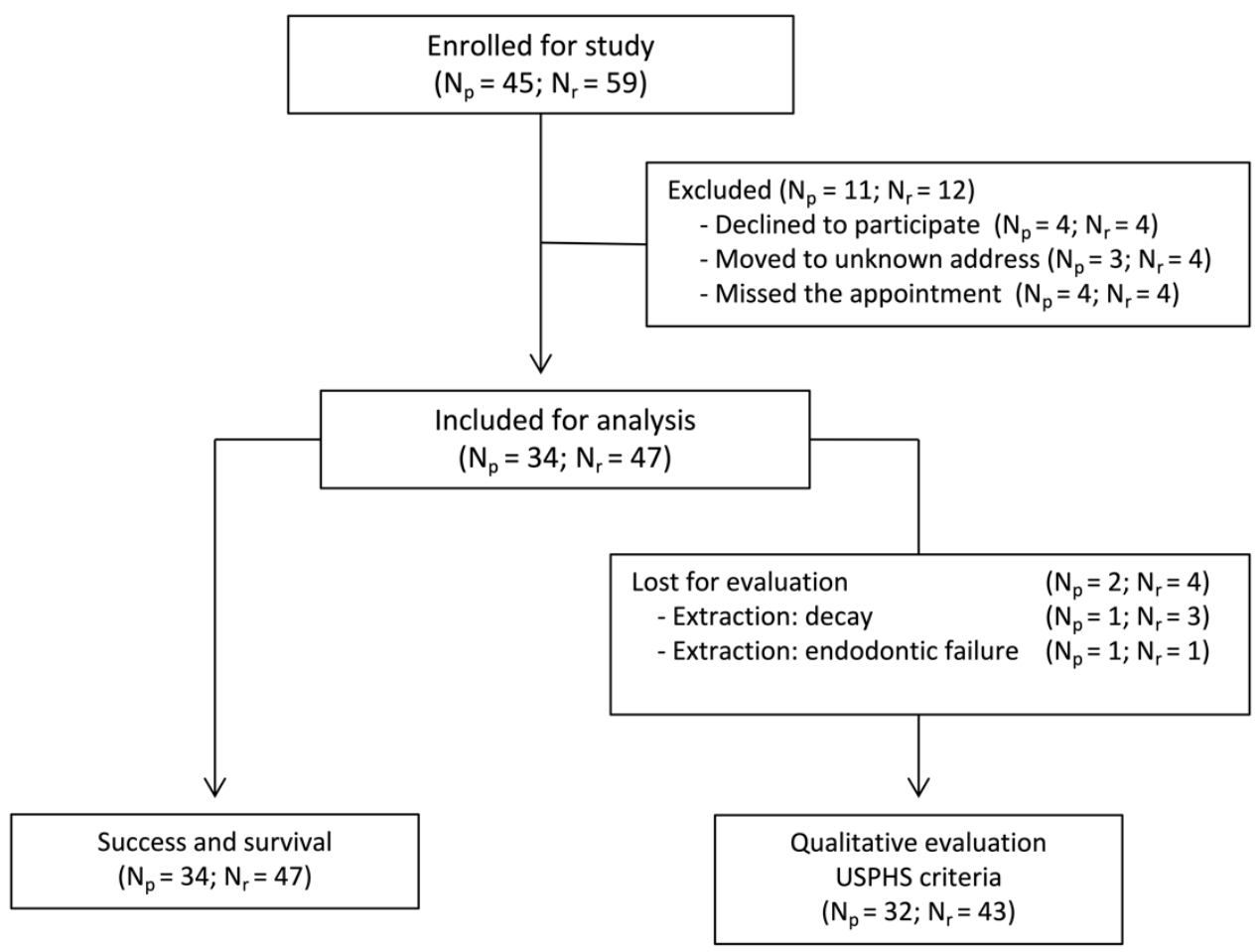

Figure 1. Flow chart $\left(\mathrm{N}_{\mathrm{p}}=\right.$ number of patients; $\mathrm{N}_{\mathrm{r}}=$ number of restorations).

An overall restoration survival rate of $91.4 \%$ was found after a mean follow-up of $28 \pm 8$ months (range 14-44 months). Three onlays were lost for follow-up due to extraction following rampant drug-induced cervical caries in one patient. One tooth with a fractured endocrown and a large periapical lesion was extracted. The overall restoration success rate was $87.2 \%$. In one patient, two teeth with an overlay developed secondary caries, which was treated by removing the decay and placing a direct composite filling without removing the onlays. Figure 2 presents the number of USPHS-scored restorations per time frame.

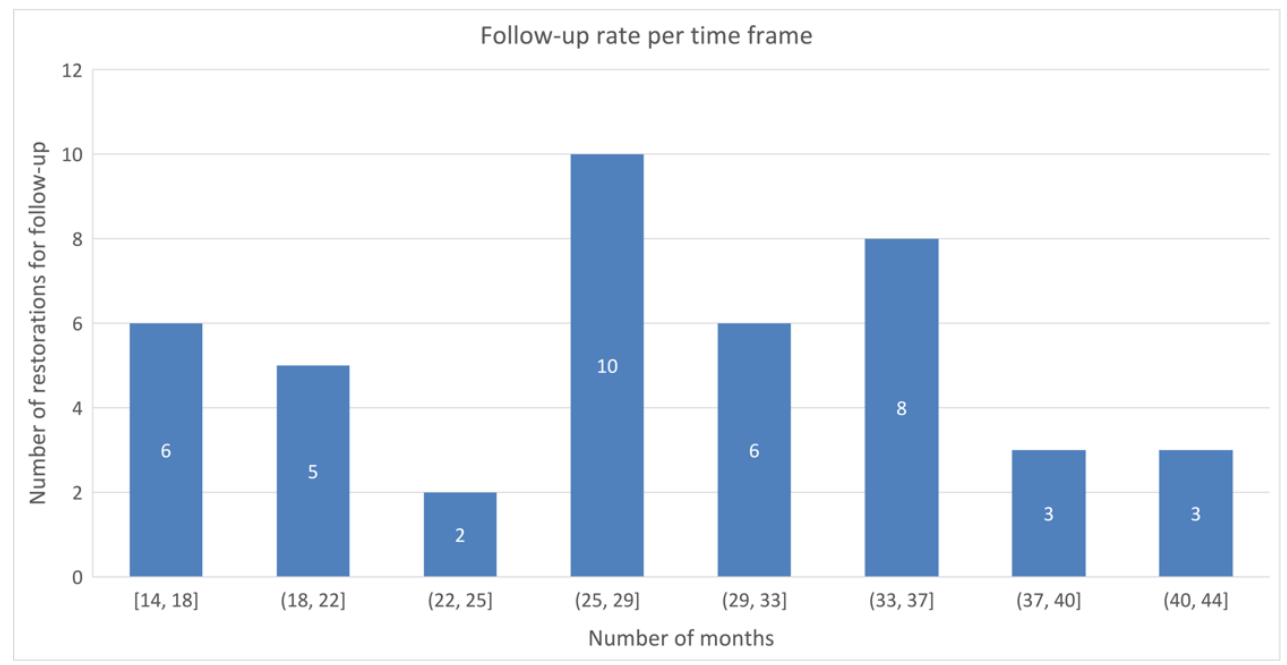

Figure 2. Follow-up rate per time frame.

In Figure 3, an example case of 36 month follow-up on the lower left first molar onlay is shown. Although no marginal discoloration is visible, a marginal gap has formed on the occlusal margin after 36 months and was rated as Bravo. The follow-up time length on the 
lower left second premolar is 27 months. Here, a small occlusal marginal gap was reported and scored as Bravo for marginal adaptation; both onlays received a Bravo score for surface texture due to loss of luster. The baseline and endpoint scores of the USPHS categorical criteria are shown in Table 5. The scores remained relatively unchanged for all restoration types at a $\geq 95 \%$ Alpha over an averaged 28-month period for retention, secondary caries, and anatomic form. In terms of color match, $49 \%$ of restorations were scored as Alpha, $42 \%$ as Bravo, and $9 \%$ as Charlie at baseline. Differences between color match USPHS scores at baseline, and at endpoint they were statistically significant (Wilcoxon's test; $\mathrm{Z}=-2.840$; $p$ < 0.05). Marginal discoloration scores dropped from $100 \%$ Alpha at baseline to $84 \%$ Alpha and $16 \%$ Bravo at endpoint, which was predominantly registered in onlays $(Z=-2.646$; $p<0.05)$. With respect to marginal adaptation, the baseline 100\% Alpha score dropped to $72 \%$ and a $28 \%$ Bravo score, which was again predominantly related to onlays and, in a lesser degree, to overlays. Scores at baseline and at endpoint were significantly different $(Z=-3.464 ; p<0.001)$. Surface texture showed a statistically significant difference between the baseline (100\% Alpha) and endpoint (53\% Alpha and 47\% Bravo; $Z=-4.472 ; p<0.001)$, affecting all three restoration types. In general, endocrowns presented the smallest drop of categorical scores over the observation period, and inlays and onlays the greatest. An independent samples Kruskal-Wallis test showed statistically significant differences between restoration types for marginal discoloration $(\mathrm{H}=13.675 ; p<0.05)$ and marginal adaptation $(\mathrm{H}=25.124 ; p<0.001)$. When comparing restoration types pairwise, inlays and onlays showed a significantly greater drop for marginal discoloration than overlays $(\mathrm{H}=9.726 ; p<0.05)$ and endocrowns $(\mathrm{H}=10.750 ; p<0.05)$ Marginal adaptation scores were significantly lower for inlays and onlays compared to overlays $(\mathrm{H}=15.869 ; p<0.001)$ and endocrowns $(\mathrm{H}=17.917 ; p<0.001)$. Chi-square test results are displayed in Table 5, showing the same outcomes as the above described tests.

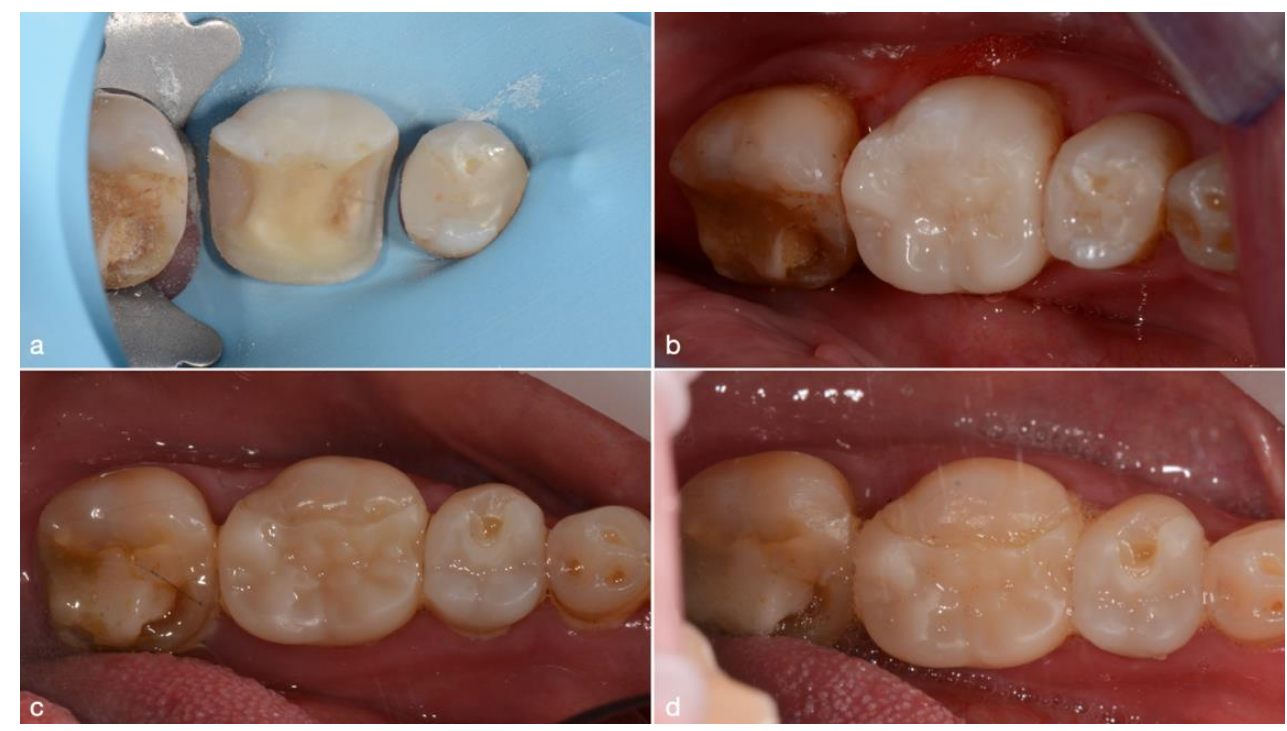

Figure 3. Images and descriptions of follow-up cases. Marginal adaptation: (a) Preparation at placement appointment; (b) immediately after placement of onlay on \#36; (c) unintentional follow-up after 7 months of \#36 due to placement of onlay on \#35; (d) 36-month follow-up of \#36.

The median and interquartile range of patient and operator satisfaction scores are depicted in Figure 4. The overall mean VAS score for patient satisfaction was $86.5 \% \pm 10.2 \%$ versus $77.0 \% \pm 10.6 \%$ for operator satisfaction. The mean VAS score for patient satisfaction with the IOS procedure was $77.1 \% \pm 24.7 \%$, while satisfaction with the esthetic result and functionality of the restoration were $92.0 \% \pm 7.0 \%$ and $90.6 \% \pm 8.9 \%$, respectively. For operator satisfaction, a mean VAS score of $70.7 \% \pm 18.7 \%$ was calculated with the overall digital workflow, $71.7 \% \pm 24.1 \%$ with the IOS procedure, $75.9 \% \pm 21.5 \%$ with the virtual designing 
of the restoration, $80.8 \% \pm 15.6 \%$ with the placement of the restoration, $83.7 \% \pm 12.7 \%$ with the esthetic appearance, $76.4 \% \pm 17.3 \%$ with the color, and $83.0 \% \pm 16.9 \%$ with the anatomical shape of the restoration. In addition, $95.6 \%$ of the operators preferred the IOS procedure over conventional impression taking.

Table 5. USPHS scores and Chi-Square statistics at baseline and endpoint per restoration type.

\begin{tabular}{|c|c|c|c|c|c|c|c|c|c|c|}
\hline \multirow[b]{2}{*}{ Category } & \multicolumn{5}{|c|}{ Baseline } & \multicolumn{5}{|c|}{ Recall Session } \\
\hline & In/onlays & Overlays & Endocrowns & Total & Chi-Squared & In/onlays & Overlays & Endocrowns & Total & Chi-Squared \\
\hline & $N$ & $N$ & $N$ & $N(\%)$ & $p$ & $N$ & $N$ & $N$ & $N(\%)$ & $p$ \\
\hline $\begin{array}{l}\text { Retention } \\
\text { Alpha }\end{array}$ & 12 & 21 & 10 & $43(100)$ & - & 12 & 21 & 10 & $43(100)$ & - \\
\hline $\begin{array}{c}\text { Color match } \\
\text { Alpha } \\
\text { Bravo } \\
\text { Charlie }\end{array}$ & $\begin{array}{l}8 \\
4 \\
0\end{array}$ & $\begin{array}{l}10 \\
9 \\
2\end{array}$ & $\begin{array}{l}3 \\
5 \\
2\end{array}$ & $\begin{array}{c}21(49) \\
18(42) \\
4(9)\end{array}$ & 0.375 & $\begin{array}{c}2 \\
10 \\
0\end{array}$ & $\begin{array}{c}7 \\
12 \\
2\end{array}$ & $\begin{array}{l}2 \\
5 \\
3\end{array}$ & $\begin{array}{c}11(26) \\
27(63) \\
5(11)\end{array}$ & 0.162 \\
\hline $\begin{array}{c}\text { Marginal } \\
\text { discoloration } \\
\text { Alpha } \\
\text { Bravo }\end{array}$ & $\begin{array}{c}12 \\
0\end{array}$ & $\begin{array}{c}21 \\
0 \\
\end{array}$ & $\begin{array}{c}10 \\
0\end{array}$ & $\begin{array}{c}43(100) \\
0\end{array}$ & - & $\begin{array}{l}6 \\
6 \\
\end{array}$ & $\begin{array}{c}20 \\
1 \\
\end{array}$ & $\begin{array}{c}10 \\
0\end{array}$ & $\begin{array}{c}36(84) \\
7(16)\end{array}$ & $<0.001$ \\
\hline $\begin{array}{c}\text { Secondary } \\
\text { caries } \\
\text { Alpha } \\
\text { Charlie }\end{array}$ & $\begin{array}{c}12 \\
0 \\
\end{array}$ & $\begin{array}{c}21 \\
0 \\
\end{array}$ & $\begin{array}{c}10 \\
0 \\
\end{array}$ & $\begin{array}{c}43(100) \\
0\end{array}$ & - & $\begin{array}{c}12 \\
0\end{array}$ & $\begin{array}{c}19 \\
2\end{array}$ & $\begin{array}{c}10 \\
0\end{array}$ & $\begin{array}{c}41(95) \\
2(5)\end{array}$ & 0.333 \\
\hline $\begin{array}{l}\text { Anatomic } \\
\text { form } \\
\text { Alpha } \\
\text { Bravo }\end{array}$ & $\begin{array}{c}12 \\
0\end{array}$ & $\begin{array}{c}21 \\
0\end{array}$ & $\begin{array}{c}10 \\
0\end{array}$ & $\begin{array}{c}43(100) \\
0\end{array}$ & - & $\begin{array}{c}12 \\
0\end{array}$ & $\begin{array}{c}19 \\
2\end{array}$ & $\begin{array}{c}10 \\
0\end{array}$ & $\begin{array}{c}41(95) \\
2(5)\end{array}$ & 0.333 \\
\hline $\begin{array}{c}\text { Marginal } \\
\text { adaptation } \\
\text { Alpha } \\
\text { Bravo }\end{array}$ & $\begin{array}{c}12 \\
0\end{array}$ & $\begin{array}{c}21 \\
0\end{array}$ & $\begin{array}{c}10 \\
0\end{array}$ & $\begin{array}{c}43(100) \\
0\end{array}$ & - & $\begin{array}{c}2 \\
10 \\
\end{array}$ & $\begin{array}{c}19 \\
2\end{array}$ & $\begin{array}{c}10 \\
0\end{array}$ & $\begin{array}{l}31(72) \\
12(28)\end{array}$ & $<0.001$ \\
\hline $\begin{array}{c}\text { Surface } \\
\text { texture } \\
\text { Alpha } \\
\text { Bravo }\end{array}$ & $\begin{array}{c}12 \\
0\end{array}$ & $\begin{array}{c}21 \\
0\end{array}$ & $\begin{array}{c}10 \\
0\end{array}$ & $\begin{array}{c}43(100) \\
0\end{array}$ & - & $\begin{array}{l}5 \\
7\end{array}$ & $\begin{array}{c}12 \\
9\end{array}$ & $\begin{array}{l}6 \\
4\end{array}$ & $\begin{array}{l}23(53) \\
20(47)\end{array}$ & 0.620 \\
\hline
\end{tabular}

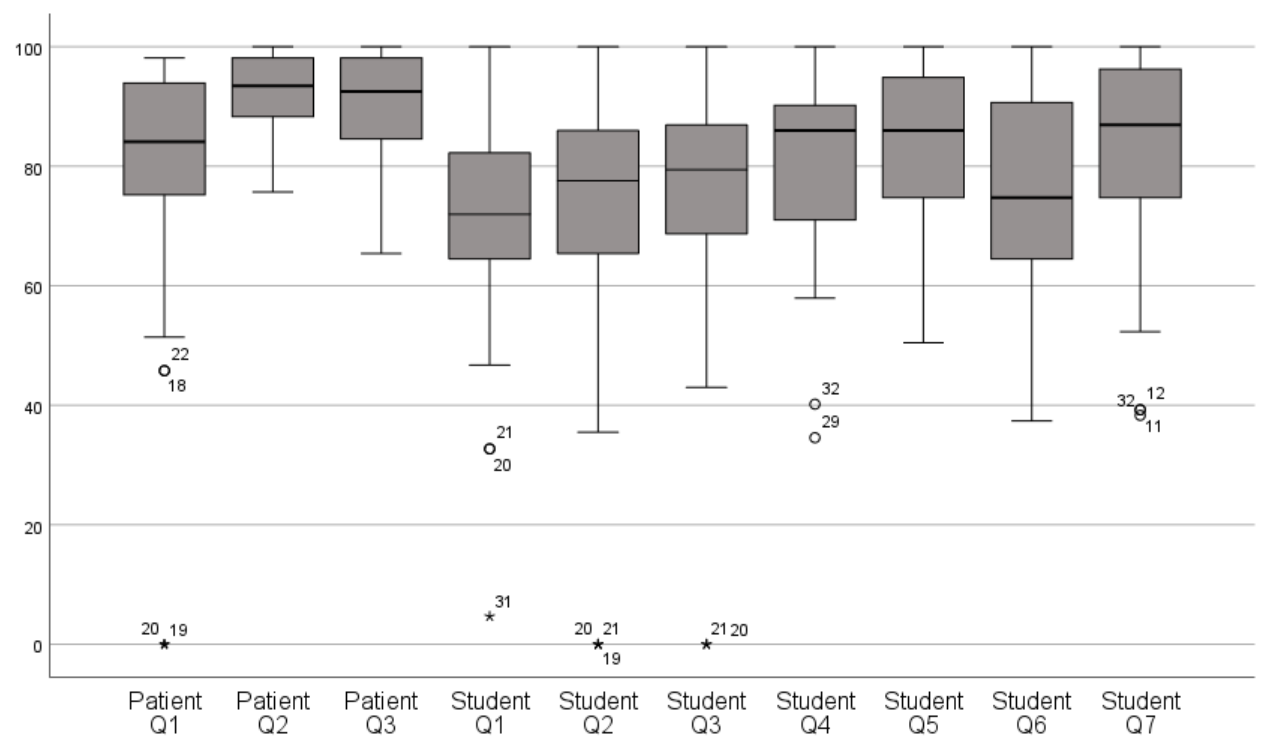

Figure 4. Boxplot with median and interquartile range of patient and operator VAS scores. $\left({ }^{\circ}=\right.$ outliers $^{*}{ }^{*}=$ most extreme outlier; numbers $=$ case numbers.$)$

A statistically significant correlation was found between mean patient and operator satisfaction (Spearman's $\rho=0.609 ; p<0.01$ ). The mean overall VAS scores showed a statistically significant difference between patients and operators $(\mathrm{Z}=-4.375 ; p<0.001)$. 


\section{Discussion}

The present prospective study evaluated the survival, success, and clinical performance of Lava Ultimate restorations, and the patient and operator satisfaction related to the restorative intervention. All restorations were prepared and installed in an academic setting by undergraduate students who received previous training. To the authors' knowledge, no study to date has analyzed the clinical outcomes of Lava Ultimate over a period longer than two years, and no satisfaction reports have yet been published on this treatment approach. In the clinical report of Zimmerman et al. [39], a clinical success rate of $95.0 \%$ after 12 months and of $85.7 \%$ after 24 months was determined, with debonding as most prominent complication. Our results confirmed a clinical success rate of $87.2 \%$ after a mean $28 \pm 8$ months follow-up period, with secondary caries as the only complication. Although several authors related debonding to the physicochemical properties of Lava Ultimate, no such complications were registered in our patient sample. In this respect, previous studies have reported on the effect of material conditioning for optimizing the adhesive behavior of particle-filled composite resin. In an in vitro setting, Frankenberger et al. [40] evaluated the microtensile bond strength of Lava Ultimate, e.Max CAD, Celtra Duo, and Vita Enamic, and they concluded that sandblasting without application of hydrofluoric acid and silane produced the highest bond strength values for Lava Ultimate (17.9 $\pm 4.5 \mathrm{MPa})$, but this is still inferior to those of lithium disilicate ceramic $(26.3 \pm 7.7 \mathrm{MPa})$. One possible explanation for this is, since no ceramic scaffold is available for microretentive anchorage, particle-filled composite resin materials might be more susceptible to debonding. Rosentritt et al. [41] reported a high incidence of debonding of Lava Ultimate restorations and postulated that this might be attributed to a swelling of the restoration after water absorption in combination with deformation of the highly elastic material under occlusal loading. Lava Ultimate thus seems to have weaker mechanical properties than other materials such as glass ceramic alternatives, entailing more complications over extended periods in function.

Several factors might influence restoration survival and success, including patientrelated caries risk and occlusal load [42-44]; in addition, the clinical experience of the operator may contribute to differences in treatment outcomes. The latter involves not only the designing of the preparation, the execution and accuracy of the IOS, but also the cementation procedure and finishing of the restoration [45]. In order to limit the influence of these factors, patients with high caries risk were excluded from the study at baseline. The abutment preparation and the designing and finishing of the restoration were carried out according to the prevailing guidelines as taught in the undergraduate training. On the other hand, patients with parafunctional habits or heavy wear facets were not excluded from the study, which probably may have affected the clinical outcomes of the restorations.

In contrast to most clinical studies, the restorations were placed by undergraduate students exclusively, albeit after thorough training and supervised by calibrated clinical instructors. Prior to the start of the study, all operators received clinical IOS training. As confirmed by previous authors, repeated clinical training before the actual treatment decreases the time needed for a digital full arch scan and significantly improves the accuracy of the digital impression [46,47]. In a similar study setup, Zimmerman et al. [48] reported that almost all undergraduate students (95\%) wanted the CAD/CAM method to be integrated in their regular courses, which is in line of our poll among our operators ( $95.7 \%$ chose digital as preferred impression method).

In some cases, minor adjustments at the occlusal and approximal surface were done to ensure a correct seating and occlusal contact. Discrepancies in the fit and occlusal and approximal contacts could be caused by errors in the digital impression, attributable to the type and calibration of the device, the IOS method, and operator experience [12]. The accuracy of IOS also depends on the extent of the scanning region and decreases when the scanning surface increases [49]. In spite of these adjustments, the placement of the restoration was rated a mean VAS score of $80.8 \% \pm 15.6 \%$, which was in line with the report of Joda et al. [50], confirming that the digital workflow entailed less adjustments than the conventional workflow. The high accuracy and reproducibility of the IOS method, the 
simplified CAD/CAM fabrication process, and the limited need for manual interventions, are likely to result in a higher output accuracy, thus allowing for less room for flaws or irregularities [50,51]. For future clinical studies, it could be recommended to run customized training programs for undergraduate students depending on the individual level of skill and the IOS system in use. This might reduce the level of difficulty and the scanning time and might increase the accuracy of the scans $[9-13,15-17,46-48,50]$.

The clinical performance of Lava Ultimate restorations has previously been studied using either the USPHS [37] or FDI criteria [35,36,39,52]. The USPHS criteria used in this study do not fully comply with the modified set proposed by Fasbinder et al. [37], who added extra subset scores for most of the criteria except for color match and anatomic form. Our findings indicated a significant drop in USPHS scores at the endpoint for color match, marginal discoloration, marginal adaptation, and surface texture. Although the sample sizes of the restoration type subgroups were small, there was strong statistical evidence confirming the significant differences between inlays/onlays and the other restoration types. The color of the restorations mimicked the adjacent tooth structure (USPHS Alpha score) in $26 \%$ at endpoint, while $63 \%$ were found to have an acceptable mismatch (USPHS Bravo score), and $11 \%$ showed an unacceptable color mismatch (USPHS Charlie score). In the study of Zimmerman et al. [39], 13\% of restorations mimicked the adjacent tooth color, and $87 \%$ showed acceptable minor or clear discrepancies in color match. Souza et al. [35] assigned a good color match to $25 \%$ of Lava Ultimate restorations and a minor or distinct but acceptable color deviation with the adjacent tooth structure to $75 \%$, which was better than the IPS e-max CAD onlays in a split-mouth design. Only Fasbinder et al. [37] reported an almost ideal (93\%) match between tooth and restoration after 5 years, which was comparable to leucite reinforced ceramic. Lava Ultimate blocks, however, are available in a limited range of monochromatic colors. The often-marked shade gradient of natural tooth surfaces and the absence of an esthetic bevel preparation for this type of restorative material may account for several color mismatches, although on the other hand, particle-filled composite materials appear to be more susceptible to discoloration compared to dental ceramics $[28,30,53]$. In addition, the FDI and USPHS criteria used for color evaluation lack objectivity and evaluator calibration, which could account for some distinct differences between studies.

Marginal discoloration without axial penetration (USPHS bravo score) was found in $16 \%$ of restorations, which was statistically significantly correlated with inlays and onlays. Zimmerman et al. [39] reported marginal staining in $60 \%$ of Lava Ultimate restorations after 24 months. Fasbinder found an unchanged marginal discoloration score over 5 years of over $93 \%$, while Souza et al. and Tunac et al. reported an $85 \%$ and $96 \%$ fraction, respectively, showing stainless margins. To the best of our knowledge, Zimmerman et al. [39] did not use IDS and applied a dual cure adhesive from another brand rather than the restorative material (Variolink II, Ivoclar Vivadent AG, Schaan, Lichtenstein). Both Tunac et al. [36] and Souza et al. [35] used the 10-MDP containing Rely X Ultimate adhesive system (3M, St. Paul, MN, USA). Fasbinder et al. [37] compared the abovementioned luting cements but did not find any significant difference over a 5-year follow-up period. Based on the above and present findings, IDS in combination with a self-etching and 10-MDP containing universal adhesive and a dual cure composite cement after airborne particle abrasion of both the receiving abutment and restoration intaglio appears to produce the most favorable bonding performance. This was also suggested in the in-vitro study of Kömürcüoğlu et al. [54].

With respect to marginal adaptation, a detectable but clinically acceptable margin (USPHS bravo score) was found in $28 \%$ of the restorations, producing a statistically significant difference $(\mathrm{Z}=-3.464 ; p<0.001)$ between the baseline and endpoint scores with a strong correlation to inlays and onlays compared to overlays $(H=15.869 ; p<0.001)$ and endocrowns $(\mathrm{H}=17.917 ; p<0.001)$. Fasbinder et al. [37] reported detectable margins along less than $50 \%$ of cavosurface margin and less than $1 \mathrm{~mm}$ in depth after 5 years in $77 \%$ of Lava Ultimate restorations as opposed to $87 \%$ in glass ceramic restorations. This was most obvious at the occlusal margins, where the cement gap seems to wear faster than the 
restoration. Tunac et al. [36] reported small marginal gaps that are removable by polishing (150-micron grid) in 5\% of Lava Ultimate inlays after 2 years of function. A harmonious outline without gaps was reported in $83 \%$ of restorations by Zimmerman et al. [39] and in $90 \%$ by Souza et al. [39]. Marginal integrity is one of the most important factors in rating a restoration's success. Even in restorations with clinically acceptable margins, disruption of the marginal seal caused by material instability or disintegration of the luting cement, as previously documented in ceramic restorations, may occur over time. The low wear resistance and low stiffness of Lava Ultimate may expose restorations to marginal step formation, in contrast to the gap observed in ceramic restorations $[35,42,55]$. It follows that the marginal adaptation of Lava Ultimate restoration should be closely monitored during successive follow-up sessions.

In $44 \%$ of restorations, the surface texture was scored rougher than enamel, albeit clinically acceptable (USPHS Bravo score). Zimmerman et al. [39] reported a slight but polishable dullness in 50\% of mixed-type restorations after 24 months. Souza et al. [35]. Found that only $10 \%$ of the restorations kept a high surface luster. Tunac et al. [36] found similar surface changes in only $2 \%$ of Lava Ultimate inlays, and Fasbinder et al. [37] reported a loss of surface gloss without affecting texture in $7 \%$ of Lava Ultimate onlays, which was equal to glass ceramic onlays as part of their study. Although high incidences of surface luster loss were reported in all available studies, none were reported to be clinically unacceptable. Koizumi et al. [56] postulated that surface roughness and related luster of resin composite indirect restorations might further be influenced by external factors, such as toothbrush abrasion.

To the best of the authors' knowledge, this is the first study reporting patient and operator satisfaction with CAD/CAM-fabricated resin composite restorations and related clinical workflow using the visual analogue scale (VAS) questionnaire [57]. In this study, the VAS was selected since it appears to be significantly more sensitive to registering small nuances in comparison to scales with defined categorical response options (very satisfied, satisfied, not satisfied, etc.), as used by other authors [39]. Although the mean overall VAS scores differed significantly between patients and operators $(p<0.001)$, satisfaction on the IOS procedure was comparable $(77.1 \% \pm 24.7 \%$ for patients and $71.7 \% \pm 24.1 \%$ for operators), whereas on the other hand, the esthetic result was scored significantly poorer by operators (i.e., $83.7 \% \pm 12.7 \%$, versus $92.0 \% \pm 7.0 \%$ by patients). The latter was in line of the findings of Zimmerman et al. [48], and it most probably reflects the more critical attitude of dental professionals, who are additionally trained to detect small color differences under dental operatory light. The significant correlation between patient and operator VAS scores $(p<0.01)$ suggests that a number of factors such as, for instance, the location, stage of deterioration and color of the treated tooth, restoration type, and accessibility of the abutment margins in terms of sulcus widening and margin isolation, probably might have influenced the individual appraisal of both the treatment flow and the restorative outcome. Finally, $95.6 \%$ of the operators preferred digital over analogue impression taking, which was also consistent with the previous report of Zimmerman et al. [48].

Some limitations must be considered when analyzing the present findings. First, no control group was included in this prospective observational study where the CAD/CAM resin composite could be compared to another direct or indirect restorative material. The focus of interest was on the clinical behavior of the at-the-time novel material class of particle filled resin composite. Previous clinical studies involving a control group indeed failed to show significant differences between the tested materials [35-37]. Furthermore, valuable data were lost by a drop-out of $20.3 \%$ and loss by extraction of $6.7 \%$ of the original study population, producing rather small sample sizes but still with enough statistical power to test our hypotheses. In addition, the variation observed between the findings of different studies may be caused by the possible inclusion of patients with dental wear and parafunctional habits, the extension of the restorations, the number of operators and evaluators, and the luting cement and procedure applied. 


\section{Conclusions}

Within these limitations, the Lava Ultimate CAD/CAM restorations exhibited good survival and success rates when placed by undergraduate students and combining IDS, sandblasting, and MDP-containing adhesive systems. Marginal disintegration may, however, present in inlays and onlays over time. Patient and operator satisfaction with IOS procedures and restorations was high, even though disagreement in satisfaction scores was found for esthetical appraisal of the finished restorations. Integrating the full digital workflow for the fabrication of partial indirect restorations in the undergraduate training program may represent an important asset based on a manageable learning curve and the ease and efficiency of the procedure.

Author Contributions: Conceptualization, S.V.; formal analysis, V.V. and P.D.C.; investigation, V.V.; methodology, V.V. and S.V.; project administration, S.V.; validation, V.V.; writing-original draft, V.V.; writing-review and editing, P.D.C. and S.V. All authors have read and agreed to the published version of the manuscript.

Funding: This research was supported by 3M Oral Care. (A15/TT/09480).

Institutional Review Board Statement: The study was conducted according to the guidelines of the Declaration of Helsinki, and approved by the Ethical Committee of the Ghent University Hospital (2015/0144).

Informed Consent Statement: Informed consent was obtained from all subjects involved in the study.

Data Availability Statement: Data are available from the corresponding author upon request.

Conflicts of Interest: Stefan Vandeweghe received a grant from 3M Oral Care.

\section{References}

1. Guth, J.F.; Runkel, C.; Beuer, F.; Stimmelmayr, M.; Edelhoff, D.; Keul, C. Accuracy of five intraoral scanners compared to indirect digitalization. Clin. Oral Investig. 2017, 21, 1445-1455. [CrossRef]

2. Shembesh, M.; Ali, A.; Finkelman, M.; Weber, H.P.; Zandparsa, R. An In Vitro Comparison of the Marginal Adaptation Accuracy of CAD/CAM Restorations Using Different Impression Systems. J. Prosthodont. 2017, 26, 581-586. [CrossRef]

3. Su, T.S.; Sun, J. Comparison of marginal and internal fit of 3-unit ceramic fixed dental prostheses made with either a conventional or digital impression. J. Prosthet. Dent. 2016, 116, 362-367. [CrossRef] [PubMed]

4. Dauti, R.; Cvikl, B.; Lilaj, B.; Heimel, P.; Moritz, A.; Schedle, A. Micro-CT evaluation of marginal and internal fit of cemented polymer infiltrated ceramic network material crowns manufactured after conventional and digital impressions. J. Prosthodont. Res. 2019, 63, 40-46. [CrossRef] [PubMed]

5. Nedelcu, R.; Olsson, P.; Nystrom, I.; Ryden, J.; Thor, A. Accuracy and precision of 3 intraoral scanners and accuracy of conventional impressions: A novel in vivo analysis method. J. Dent. 2018, 69, 110-118. [CrossRef]

6. Muhlemann, S.; Benic, G.I.; Fehmer, V.; Hammerle, C.H.F.; Sailer, I. Clinical quality and efficiency of monolithic glass ceramic crowns in the posterior area: Digital compared with conventional workflows. Int. J. Comput. Dent. 2018, 21, 215-223.

7. Muhlemann, S.; Benic, G.I.; Fehmer, V.; Hammerle, C.H.F.; Sailer, I. Randomized controlled clinical trial of digital and conventional workflows for the fabrication of zirconia-ceramic posterior fixed partial dentures. Part II: Time efficiency of CAD-CAM versus conventional laboratory procedures. J. Prosthet. Dent. 2019, 121, 252-257. [CrossRef]

8. Sailer, I.; Benic, G.I.; Fehmer, V.; Hammerle, C.H.F.; Muhlemann, S. Randomized controlled within-subject evaluation of digital and conventional workflows for the fabrication of lithium disilicate single crowns. Part II: CAD-CAM versus conventional laboratory procedures. J. Prosthet. Dent. 2017, 118, 43-48. [CrossRef] [PubMed]

9. Al Hamad, K.Q. Learning curve of intraoral scanning by prosthodontic residents. J. Prosthet. Dent. 2020, 123, 277-283. [CrossRef]

10. Kim, J.; Park, J.-M.; Kim, M.; Heo, S.-J.; Shin, I.H.; Kim, M. Comparison of experience curves between two 3-dimensional intraoral scanners. J. Prosthet. Dent. 2016, 116, 221-230. [CrossRef]

11. Marti, A.M.; Harris, B.T.; Metz, M.J.; Morton, D.; Scarfe, W.C.; Metz, C.J.; Lin, W.S. Comparison of digital scanning and polyvinyl siloxane impression techniques by dental students: Instructional efficiency and attitudes towards technology. Eur. J. Dent. Educ. 2017, 21, 200-205. [CrossRef] [PubMed]

12. Joda, T.; Lenherr, P.; Dedem, P.; Kovaltschuk, I.; Bragger, U.; Zitzmann, N.U. Time efficiency, difficulty, and operator's preference comparing digital and conventional implant impressions: A randomized controlled trial. Clin. Oral Implant. Res. 2017, 28, 1318-1323. [CrossRef] [PubMed]

13. Zitzmann, N.U.; Kovaltschuk, I.; Lenherr, P.; Dedem, P.; Joda, T. Dental Students' Perceptions of Digital and Conventional Impression Techniques: A Randomized Controlled Trial. J. Dent. Educ. 2017, 81, 1227-1232. [CrossRef] 
14. Schott, T.C.; Arsalan, R.; Weimer, K. Students' perspectives on the use of digital versus conventional dental impression techniques in orthodontics. BMC Med. Educ. 2019, 19, 81. [CrossRef] [PubMed]

15. Cheah, C.; Lim, C.; Ma, S. The dentist will scan you now: The next generation of digital-savvy graduates. Eur. J. Dent. Educ. 2021, 25, 232-237. [CrossRef]

16. Ahmed, K.E.; Peres, K.G.; Peres, M.A.; Evans, J.L.; Quaranta, A.; Burrow, M.F. Operators matter-An assessment of the expectations, perceptions, and performance of dentists, postgraduate students, and dental prosthetist students using intraoral scanning. J. Dent. 2021, 105, 103572. [CrossRef]

17. Ahmed, K.E.; Wang, T.; Li, K.Y.; Luk, W.K.; Burrow, M.F. Performance and perception of dental students using three intraoral CAD/CAM scanners for full-arch scanning. J. Prosthodont. Res. 2019, 63, 167-172. [CrossRef]

18. Zarone, F.; Ferrari, M.; Mangano, F.G.; Leone, R.; Sorrentino, R. “Digitally Oriented Materials”: Focus on Lithium Disilicate Ceramics. Int. J. Dent. 2016, 2016, 9840594. [CrossRef]

19. Aslan, Y.U.; Uludamar, A.; Ozkan, Y. Retrospective Analysis of Lithium Disilicate Laminate Veneers Applied by Experienced Dentists: 10-Year Results. Int. J. Prosthodont. 2019, 32, 471-474. [CrossRef] [PubMed]

20. Malament, K.A.; Natto, Z.S.; Thompson, V.; Rekow, D.; Eckert, S.; Weber, H.P. Ten-year survival of pressed, acid-etched e.max lithium disilicate monolithic and bilayered complete-coverage restorations: Performance and outcomes as a function of tooth position and age. J. Prosthet. Dent. 2019, 121, 782-790. [CrossRef]

21. Rauch, A.; Reich, S.; Dalchau, L.; Schierz, O. Clinical survival of chair-side generated monolithic lithium disilicate crowns: 10-Year results. Clin. Oral Investig. 2018, 22, 1763-1769. [CrossRef] [PubMed]

22. Baladhandayutham, B.; Lawson, N.C.; Burgess, J.O. Fracture load of ceramic restorations after fatigue loading. J. Prosthet. Dent. 2015, 114, 266-271. [CrossRef] [PubMed]

23. Hamza, T.A.; Sherif, R.M. Fracture Resistance of Monolithic Glass-Ceramics Versus Bilayered Zirconia-Based Restorations. J. Prosthodont. 2019, 28, e259-e264. [CrossRef] [PubMed]

24. Carrabba, M.; Keeling, A.J.; Aziz, A.; Vichi, A.; Fonzar, R.F.; Wood, D.; Ferrari, M. Translucent zirconia in the ceramic scenario for monolithic restorations: A flexural strength and translucency comparison test. J. Dent. 2017, 60, 70-76. [CrossRef] [PubMed]

25. Baldissara, P.; Wandscher, V.F.; Marchionatti, A.M.E.; Parisi, C.; Monaco, C.; Ciocca, L. Translucency of IPS e.max and cubic zirconia monolithic crowns. J. Prosthet. Dent. 2018, 120, 269-275. [CrossRef] [PubMed]

26. Zadeh, P.N.; Lumkemann, N.; Sener, B.; Eichberger, M.; Stawarczyk, B. Flexural strength, fracture toughness, and translucency of cubic/tetragonal zirconia materials. J. Prosthet. Dent. 2018, 120, 948-954. [CrossRef]

27. Mainjot, A.K.; Dupont, N.M.; Oudkerk, J.C.; Dewael, T.Y.; Sadoun, M.J. From Artisanal to CAD-CAM Blocks: State of the Art of Indirect Composites. J. Dent. Res. 2016, 95, 487-495. [CrossRef]

28. Lawson, N.C.; Bansal, R.; Burgess, J.O. Wear, strength, modulus and hardness of CAD/CAM restorative materials. Dent. Mater. 2016, 32, e275-e283. [CrossRef]

29. Ludovichetti, F.S.; Trindade, F.Z.; Adabo, G.L.; Pezzato, L.; Fonseca, R.G. Effect of grinding and polishing on the roughness and fracture resistance of cemented CAD-CAM monolithic materials submitted to mechanical aging. J. Prosthet. Dent. 2019, 121, 866.e861-866.e868. [CrossRef]

30. Awada, A.; Nathanson, D. Mechanical properties of resin-ceramic CAD/CAM restorative materials. J. Prosthet. Dent. 2015, 114, 587-593. [CrossRef]

31. Nguyen, J.F.; Migonney, V.; Ruse, N.D.; Sadoun, M. Resin composite blocks via high-pressure high-temperature polymerization. Dent. Mater. Off. Publ. Acad. Dent. Mater. 2012, 28, 529-534. [CrossRef] [PubMed]

32. Nguyen, J.F.; Ruse, D.; Phan, A.C.; Sadoun, M.J. High-temperature-pressure polymerized resin-infiltrated ceramic networks. J. Dent. Res. 2014, 93, 62-67. [CrossRef] [PubMed]

33. Batalha-Silva, S.; De Andrada, M.A.C.; Maia, H.P.; Magne, P. Fatigue resistance and crack propensity of large MOD composite resin restorations: Direct versus CAD/CAM inlays. Dent. Mater. 2013, 29, 324-331. [CrossRef]

34. Dejak, B.; Młotkowski, A. A comparison of stresses in molar teeth restored with inlays and direct restorations, including polymerization shrinkage of composite resin and tooth loading during mastication. Dent. Mater. 2015, 31, e77-e87. [CrossRef]

35. Souza, J.; Fuentes, M.V.; Baena, E.; Ceballos, L. One-year clinical performance of lithium disilicate versus resin composite CAD/CAM onlays. Odontology 2021, 109, 259-270. [CrossRef] [PubMed]

36. Tunac, A.T.; Celik, E.U.; Yasa, B. Two-year performance of CAD/CAM fabricated resin composite inlay restorations: A randomized controlled clinical trial. J. Esthet. Restor. Dent. 2019, 31, 627-638. [CrossRef] [PubMed]

37. Fasbinder, D.J.; Neiva, G.F.; Heys, D.; Heys, R. Clinical evaluation of chairside Computer Assisted Design/Computer Assisted Machining nano-ceramic restorations: Five-year status. J. Esthet. Restor. Dent. 2020, 32, 193-203. [CrossRef]

38. Rabel, K.; Spies, B.C.; Pieralli, S.; Vach, K.; Kohal, R.J. The clinical performance of all-ceramic implant-supported single crowns: A systematic review and meta-analysis. Clin. Oral Implant. Res. 2018, 29 (Suppl. 18), 196-223. [CrossRef] [PubMed]

39. Zimmermann, M.; Koller, C.; Reymus, M.; Mehl, A.; Hickel, R. Clinical Evaluation of Indirect Particle-Filled Composite Resin CAD/CAM Partial Crowns after 24 Months. J. Prosthodont. 2018, 27, 694-699. [CrossRef]

40. Frankenberger, R.; Hartmann, V.E.; Krech, M.; Kramer, N.; Reich, S.; Braun, A.; Roggendorf, M. Adhesive luting of new CAD/CAM materials. Int. J. Comput. Dent. 2015, 18, 9-20.

41. Rosentritt, M.; Krifka, S.; Strasser, T.; Preis, V. Fracture force of CAD/CAM resin composite crowns after in vitro aging. Clin. Oral Investig. 2020, 24, 2395-2401. [CrossRef] 
42. Archibald, J.J.; Santos, G.C., Jr.; Santos, M.J.M.C. Retrospective clinical evaluation of ceramic onlays placed by dental students. J. Prosthet. Dent. 2018, 119, 743-748.e741. [CrossRef] [PubMed]

43. Collares, K.; Corrêa, M.B.; Laske, M.; Kramer, E.; Reiss, B.; Moraes, R.R.; Huysmans, M.-C.D.N.J.M.; Opdam, N.J.M. A practicebased research network on the survival of ceramic inlay/onlay restorations. Dent. Mater. 2016, 32, 687-694. [CrossRef] [PubMed]

44. Van de Sande, F.H.; Collares, K.; Correa, M.B.; Cenci, M.S.; Demarco, F.F.; Opdam, N. Restoration Survival: Revisiting Patients Risk Factors Through a Systematic Literature Review. Oper. Dent. 2016, 41, S7-S26. [CrossRef]

45. Zimmermann, M.; Ender, A.; Mehl, A. Local accuracy of actual intraoral scanning systems for single-tooth preparations in vitro. J. Am. Dent. Assoc. 2020, 151, 127-135. [CrossRef]

46. Waldecker, M.; Rues, S.; Trebing, C.; Behnisch, R.; Rammelsberg, P.; Bomicke, W. Effects of Training on the Execution of Complete-Arch Scans. Part 2: Scanning Accuracy. Int. J. Prosthodont. 2021, 34, 27-36. [CrossRef]

47. Waldecker, M.; Trebing, C.; Rues, S.; Behnisch, R.; Rammelsberg, P.; Bomicke, W. Effects of Training on the Execution of Complete-Arch Scans. Part 1: Scanning Time. Int. J. Prosthodont. 2021, 34, 21-26. [CrossRef]

48. Zimmermann, M.; Mormann, W.; Mehl, A.; Hickel, R. Teaching dental undergraduate students restorative CAD/CAM technology: Evaluation of a new concept. Int. J. Comput. Dent. 2019, 22, 263-271. [PubMed]

49. Imburgia, M.; Logozzo, S.; Hauschild, U.; Veronesi, G.; Mangano, C.; Mangano, F.G. Accuracy of four intraoral scanners in oral implantology: A comparative in vitro study. BMC Oral Health 2017, 17, 92. [CrossRef]

50. Joda, T.; Katsoulis, J.; Brägger, U. Clinical Fitting and Adjustment Time for Implant-Supported Crowns Comparing Digital and Conventional Workflows. Clin. Implant. Dent. Relat. Res. 2016, 18, 946-954. [CrossRef] [PubMed]

51. Dawood, A.; Purkayastha, S.; Patel, S.; MacKillop, F.; Tanner, S. Microtechnologies in implant and restorative dentistry: A stroll through a digital dental landscape. Proc. Inst. Mech. Eng. Part H 2010, 224, 789-796. [CrossRef] [PubMed]

52. Hickel, R.; Peschke, A.; Tyas, M.; Mjor, I.; Bayne, S.; Peters, M.; Hiller, K.A.; Randall, R.; Vanherle, G.; Heintze, S.D. FDI World Dental Federation-Clinical criteria for the evaluation of direct and indirect restorations. Update and clinical examples. J. Adhes. Dent. 2010, 12, 259-272. [CrossRef] [PubMed]

53. Stawarczyk, B.; Liebermann, A.; Eichberger, M.; Guth, J.F. Evaluation of mechanical and optical behavior of current esthetic dental restorative CAD/CAM composites. J. Mech. Behav. Biomed. Mater. 2015, 55, 1-11. [CrossRef] [PubMed]

54. Kömürcüoğlu, M.B.; Sağırkaya, E.; Tulga, A. Influence of different surface treatments on bond strength of novel CAD/CAM restorative materials to resin cement. J. Adv. Prosthodont. 2017, 9, 439. [CrossRef]

55. Sjogren, G.; Molin, M.; van Dijken, J.W. A 5-year clinical evaluation of ceramic inlays (Cerec) cemented with a dual-cured or chemically cured resin composite luting agent. Acta Odontol. Scand. 1998, 56, 263-267. [CrossRef]

56. Koizumi, H.; Saiki, O.; Nogawa, H.; Hiraba, H.; Okazaki, T.; Matsumura, H. Surface roughness and gloss of current CAD/CAM resin composites before and after toothbrush abrasion. Dent. Mater. J. 2015, 34, 881-887. [CrossRef]

57. Cline, M.E.; Herman, J.; Shaw, E.R.; Morton, R.D. Standardization of the visual analogue scale. Nurs. Res. 1992, 41, 378-380. [CrossRef] 